\title{
On the Innovation of Real Estate Corporate finance and Sales
}

\author{
Yan Zhu ${ }^{1, a}$ and Di Shi ${ }^{2, b}$ \\ ${ }^{1}$ School of Civil Engineering and Architecture, Southwest Petroleum University, Chengdu 610500, \\ China; \\ ${ }^{2}$ School of Geoscience and Technology, Southwest Petroleum University, Chengdu 610500, China. \\ a4459718129@qq.com, b2776341920@qq.com
}

Keywords: Real estate, finance, innovation, marketing.

\begin{abstract}
Real estate is a typical high-risk, high investment, high-return characteristics of a class of business, the more obvious characteristics of such enterprises, in addition to greater funding requirements, it also has a long turnaround time, by and large regional influence Features. As China's economy continues to develop, the real estate industry has become a force in the national economy a leader in the market economy not only stopped in her tracks, but also a firm footing. Most of the domestic real estate companies now too extensive management model, and our country has not issued the relevant regulate the real estate industry, management practices, lack of attention and execution at the macro-control, and eventually most of the domestic real estate enterprise financing problem appear. In this paper, real estate companies' modalities of future financing and sales management put forward some reasonable suggestions, hoping business in the future financing process through expanding financing channels, to structure the internal financing structure and other ways to speed up the development of enterprises.
\end{abstract}

\section{Introduction}

With the development of the times, the rapid rise of the economy, high population growth, increasing demand for our housing market, real estate development enterprises have sprung up, China's real estate industry taking shape. The real estate industry profits high, big gains, it has attracted a large number of companies investing in real estate. At present, China's real estate is in the structural adjustment period, the market environment is not stable, and this instability is mainly reflected in the changes in market demand: from the previous sellers dominate the market demand gradually transformed into the dominant buyer demand. Due to the increasingly heated competition in the real estate business, material, labor costs continue to increase, resulting in corporate profits decreased significantly. At the same time, the state government regulation of the real estate industry also has a series of changes. With the constant changes in today's real estate economy, market trends and downs, the face of these unfavorable trends, real estate companies must be upgraded in business management, with a view to getting under adverse circumstances, to maintain a competitive advantage and core competitiveness of enterprises, bound the need for more attention to real estate marketing management. Real estate sales are good or bad depends on many factors, but the most important factor is the development of enterprise marketing planning if new and unique. Comprehensive comparison of representative known real estate companies, their marketing model is mainly focused on the analysis and grasp the real estate market information, knowledge of consumer demand, and in accordance with national policies, market information and timely adjustment of the company's marketing strategy, the only way to enhance enterprise comprehensive competitiveness. Outstanding real estate companies will have excellent marketing strategies appropriate strategy.

\section{Real Estate Market Trends in China}

Most of the current development of the world's developed countries, the real estate market is relatively stable, which is by itself a long-term market adjustment and after the formation of 
government regulation. Twentieth century Japan had a serious real estate bubble, when the Japanese real estate commodity prices rise rapidly, the price in a very short period of time there is a wide range of fluctuation. This situation has attracted many investors and businesses take advantage of the rapid rise in shares of real estate investment, in all the circumstances leading to rapid increases in real estate prices of commodities. Real estate investors, speculators on the Japanese real estate market to maintain fiery attitude, causing rising real estate commodity prices, and ultimately gave birth to the entire real estate industry bubble after bubble constantly being blown big blow thick, and finally the bubble burst, the Japanese stock market suffered a serious setback, a variety of stock index futures fell crash, stock holders have to sell stocks to compensate for falling prices due to the depreciation of the loss of property. Continued until the twenty-first century, only the Japanese stock market rebound, Japan's real estate industry began to gradually recover, the current Japanese real estate market has entered a new round of growth cycle.

In 1980s when the US real estate industry after previous large-scale development has, in all aspects of the industry is also increasingly standardized and modular. But when we enter a new century, the United States there have been problems in Japan, but also the entire industry is the rapid rise in commodity prices, there is a bubble of the trend, of course, the US government according to the specific circumstances make the appropriate laws and regulations to at that time the price hedging and continued to increase rapidly rising foam. But the final result is to make people want to see - the subprime crisis broke out.

Market economy in Russia's rapid development seems half a beat slower, apparently a series of policies and regulations of the Russian government is still quite backward, most notably to the number of regulations relating to land and housing system, these laws and regulations have been extremely inconsistent with the current market environment and, so the real estate related fields in Russia is very confusing. At that time, the Russian government in order to control this situation, the development of appropriate systems for commodity housing sales and housing sale to strengthen the management, the Russian government in 2005 by the country's new "real estate law."

\section{Real Estate Financing and Marketing Studies}

For the overseas market, a series of more complete theory has been formed, which is mainly due to the many experts and scholars for more than a combination of sales strategy selection were various levels of discussion and study. There is a growing maturity of the special theory of affecting the company's sales activities namely marketing theory in the market. U.S. relevant organizations to operate sales summed up, is an organized business sales activities, which can create value. This "value" can communicate combing customer relationships, build a good relationship with the company's customers and allows the company as well as companies and organizations or clients' interests associated guaranteed. In the United States it is a famous professor Philip Kotler, who made pioneering work in the market, sales operations, and sales operations to his concept as follows: sales operations are a team, and the team as a whole through the creation of personal and other individuals or organizations are exchanged in the process nice value to their own needs. Professor Philip Kotler in the market area of sales operations has yielded fruitful results. Market-based, market can be further subdivided, the concept was first proposed by Wendell Smith. Market segmentation is a process, in this process, we can segment the different criteria, such as product quality, consumer preferences, and so on. Obviously that after such further divided, consumers in the consumer market of the same performance requirements are similar, but there are large differences in consumer demand with a difference on the consumer market. Wendell Smith, after a series of theoretical and practical studies presented on the basis of market segmentation theory, this theory has been Professor Philip Kotler through continuous research and further development, and eventually founded the STP theory, we can say without hesitation this theory of enterprise sales activities operates a milestone. This theory contains fine points of the market, target market selection and positioning, it can be called STP theory. 
4P theory of sales operations in the 1950s turned out, the theory proposed by Professor Jerome McCarthy, Professor Jerome McCarthy of the product, price, place, promotion, sales operations as a combination of four main areas, will sound where many factors summarized. $4 \mathrm{P}$ theory focuses on the role of market-oriented and that the information collected about demand for products on the market, after a certain amount of data processing can draw consumers generally accepted price of the product, while the use of a basket of goods and activities on different sales channels eventually achieve the objectives of enterprises, and earnings expectations.

In today's market economy, the rapid development of economic globalization further deepen the theoretical market operations also experienced large sales by leaps and bounds. Professor Peng Laut research and the creation of a sales marketing 4C theory in the 1980s, the main feature of this theory is to focus on consumers' preferences, while the pursuit of consumer satisfaction level of the consumers in the payment process and be able to enjoy the convenience and its cost, and take the initiative to communicate with consumers and market operators to promote the sales carried out. At the same time, 4R theory have also appeared, 4R theory focuses on the competition-oriented, but the issue has been highly controversial author theorists. One argument is that 2001 published "4R theory," by Elliot Berg Aydin, there is a saying that Don Schultz absorbed, summed up the 4C theory after theory founded 4R. $4 \mathrm{R}$ theory is better known sales operations, focusing on customer loyalty is also a business should be concerned about. Manufacturers and consumers are the two key factors that we cannot ignore, if we take into account these two factors simultaneously administered, will make marketing more efficient, because of higher degree of business interests and loyal customers can combine.

In 1993, the American Marketing experts Schultz created the integrated marketing theory, the main purpose of this theory is to establish communication with each consumer business, and on this basis to consumer preferences for the purpose of their own adjustments, recycling, using a variety of ways to promote its good corporate image and convey to consumers a unified product information, and ultimately to achieve effective two-way communication, the business brand image is maintained and consumers establish good communication channels, pathways, thereby eliminating or reducing the information asymmetry between the two, the problem of incomplete information.

\section{Conclusions}

Arrival of the new century, the rapid development of electronic science and technology, the network economy by leaps and bounds. The famous economist John network marketing network understanding: Internet marketing is the use of the Internet and its related derivatives, electronic communications and other mainstream digital media technology expenditure for the realization of marketing services. Built on a network marketing system and will certainly become a dominant force in the new marketing strategy, it will also affect the pattern of development of e-commerce today.

History of the development of real estate marketing theory tells us that whenever real estate marketing practice ushered challenges, real estate marketing theory is that when change occurs. In the real estate to return to reason, while real estate marketing strategies and methods must return to reason. Real estate companies should face the plight of real estate marketing, discard incorrect or negative real estate marketing strategy to brand building as the long-term goal to establish the correct marketing strategy, so that the healthy development of the real estate business in the fierce competition in the real estate.

\section{References}

[1] Kambhu J, Schuermann T, Stiroh KJ. Hedge Funds, Financial Intermediation, and Systemic Risk. FRNB Economic Policy Review, 13(2007)1-18.

[2] Mensah Sam, Abor Joshua Yindenaba. Agency Conflict and Bank Interest Spreads in Ghana. African Development Review-Revue Africaine De Developent. 26(2014)549-560. 
[3] Gou Feifei, Liu Jianjun, Liu Weidong, Luo Litao. A finite difference method for solving nonlinear volterra integral equation. Journal of University of Chinese Academy of Sciences. 33(2016)330-334.

[4] Pei Guihong, Yu Feng, Liu Jianjun. Feasibility Study of Individual Treatments of Desizing Wastewater. Journal of Residuals Science \& Technology. 12(2015)S85-S91.

[5] Liu Jianjun, Song Rui, Cui Mengmeng. Improvement of predictions of petrophysical transport behavior using three-dimensional finite volume element model with micro-CT images. Journal of Hydrodynamics. 27(2015)234-241.

[6] Jianjun Liu, Rui Song. Investigation of water and $\mathrm{CO}_{2}$ flooding using pore-scale reconstructed model based on micro-CT images of Berea sandstone core. Progress in Computational Fluid Dynamics, An International Journal. 15(2015)317-326.

[7] Romero LC, Gonzalez EG, Quintero ML. Measuring systemic risk in the Colombian financial system: a systemic contingent claims approach. Journal of Risk Management and Financial Institute, 6(2013)253-279

[8] Song Rui, Liu Jianjun. Study on Porosity and Permeability of Rock Core based on 3D CT Images and Structured Pore-Network Model. Journal of Southwest Petroleum University (Natural Science Edition), 37(2015)138-145.

[9] Quanshu Li, Huilin Xing, Jianjun Liu, Xiangchon Liu. A Review on Hydraulic Fracturing of Unconventional Reservoir. Petroleum, 1(2015)8-15.

[10] Yu Le, Liu Jianjun. Stability of interbed for salt cavern gas storage in solution mining considering cusp displacement catastrophe theory. Petroleum, 1(2015):82-90.

[11] Liu Jianjun, Lin Lijun, Song Rui, Zhao Jinzhou. A Pore Scale Modelling of Fluid Flow in Porous Medium Based on Navier-Stokes Equation. Disaster Advances, 6(2013)129-136.

[12] Wheaton WC. Real estate "cycles": Some fundamentals. Real Estate Economics, 27(1999)209-230. 